\title{
ESTUDO DAS CONDIÇÕES DE IMOBILIZAÇÃO DA LIPASE DE Thermomyces lanuginosus PARA A PRODUÇÃO DE BIODIESEL
}

\author{
Carolina Bordinhão ${ }^{1}$, Carla R. Matte ${ }^{2}$, Jakeline K. Poppe ${ }^{2}$, Rafael C. Rodrigues ${ }^{2}$, Plinho F. \\ Hertz $^{2}$, Marco A. Z. Ayub ${ }^{2}$. \\ ${ }^{1}$ Universidade Federal do Rio Grande do Sul, Departamento de Engenharia Química \\ ${ }^{2}$ Universidade Federal do Rio Grande do Sul. Departamento de tecnologia de alimentos \\ E-mail para contato: carolinabordinhao@gmail.com
}

RESUMO - O biodiesel é uma mistura de ésteres alquílicos de ácidos graxos que podem ser obtidos a partir da reação de transesterificação dos triglicerídeos de origem animal ou vegetal com álcoois, sendo uma alternativa substituição do convencional diesel de petróleo. A sua produção pode ser realizada pela catálise enzimática, processo que se torna ainda mais vantajoso quando se utiliza a lipase imobilizada. Neste trabalho, testamos diversos tipos de imobilização de lipases em esferas de quitosana, a fim de avaliar a estabilidade da enzima. Foram realizados testes com imobilização uni e multipontual, utilizando ativação com glicidol e com glutaraldeido. A eficiência foi analisada em virtude do rendimento de reações de produção de biodiesel, utilizando etanol e óleo de soja, e também da estabilidade frente a diversos usos. Assim, foi possível a produção de um derivado enzimático capaz de alcançar $47 \%$ de rendimento na síntese de biodiesel, sendo estável após 10 usos mantendo sua atividade inicial.

\section{INTRODUÇÃO}

O biodiesel é uma mistura de mono-alquil ésteres de ácidos graxos obtidos a partir da transesterificação dos triglicerídeos de origem animal ou vegetal com álcoois de cadeia curta, sendo uma alternativa da substituição do convencional diesel de petróleo. (DERMIBAS, 2008). Sua obtenção poder ser realizada via catálise química ou via catálise enzimática.

São diversas as vantagens de se empregar lipases como catalisadores, tais como a possibilidade de utilização de condições suaves de reação evitando a formação de subprodutos, além da possibilidade de maior controle e eficiência do processo (GARCIA et al, 2000). Lipases (triacilglicerol éster hidrolases, EC 3.1.1.3) são produzidas por microorganismos (fungos e bactérias), animais e plantas. As enzimas comerciais são derivadas principalmente de fontes microbianas devido aos baixos custos de produção e da facilidade de manipulação de suas propriedades (ANTCZAK, 2009). As lipases podem ser classificadas segundo a sua especificidade em relação à molécula ácida ou alcoólica do substrato. A lipase de Thermomyces lanuginosus, utilizada neste trabalho, é uma lipase 1,3 específica, liberando os ácidos graxos das posições 1 e 3 (CASTRO, 2004).

A imobilização de enzimas em um suporte sólido é uma tecnologia importante para a estabilização e melhoramento da atividade da enzima, sendo este processo dependente das interações químicas que ocorrem entre o suporte e as moléculas da enzima (POPPE, 2013). 
Com a imobilização, a estabilidade enzimática pode aumentar, possibilitando assim um melhor controle da reação. Além disso, o uso de enzimas imobilizadas é preferível em virtude das mesmas serem de fácil separação e remoção após o término da reação (ADRIANO, 2008).

A escolha do melhor método de imobilização deve ser baseada em parâmetros como atividade do imobilizado, estabilidade operacional, custo do procedimento de imobilização, toxicidade dos reagentes e propriedades finais desejadas para a enzima imobilizada (MENDES, 2013). Diversos tipos de imobilização têm sido empregados com lipases, como adsorção hidrofóbica, adsorção iônica, encapsulação em matrizes e ligação covalente unipontual e multipontual. Na ligação unipontual, a imobilização ocorre entre os grupos aldeído no suporte e grupos N-terminal da enzima, já na ligação multipontual, vários grupos do suporte reagem com diferentes grupos da enzima. A ligação covalente geralmente requer a realização da ativação do suporte para poder gerar grupos reativos que se unirão à enzima através de grupos laterais dos resíduos de aminoácidos (KOPP, 2014; SILVA, 2012). Diferentes métodos de ativação são avaliados, sendo o mais comum a utilização de glutaraldeido; todavia, outros compostos podem ser utilizados para ativar suportes, apresentando grupos hidroxila: o glicidol e a carbodiimida.

Sendo assim, este trabalho tem como objetivo testar diversas metodologias de imobilização para a produção de um derivado enzimático capaz de obter um melhor resultado na produção de biodiesel e possuir uma alta estabilidade em bateladas sequenciais (reusos).

\section{MATERIAIS E MÉTODOS}

\subsection{Materiais}

A lipase de T. lanuginosus (TLL, Lipolase $100 \mathrm{~L}$, forma solúvel) foi adquirida da Novozymes (Espanha). Palmitato de $p$-nitrofenila ( $p$ NPP), $p$-nitrofenol (PNP) e quitosana (a partir de cascas de camarão, $\geq 75 \%$ desacetilada), foram adquiridos a partir de Sigma Aldrich (St. Louis, EUA). Todos os outros reagentes utilizados eram de grau analítico.

\subsection{Métodos}

Preparação das partículas de quitosana: Quitosana em pó foi dissolvida em ácido acético $5 \%(\mathrm{v} / \mathrm{v})$. Para a retirada do ar da solução, esta foi sonicada por 10 minutos. A solução foi lentamente gotejada a solução coagulante de $\mathrm{NaOH}$ 0,1M (1/10) sob agitação. Em seguida, as esferas formadas foram lavadas com água destilada. As esferas foram submetidas a diferentes estratégias de imobilização, onde avaliou-se rendimento de imobilização através da equação 1 .

Rendimento da imobilização $=\frac{(\text { atividade total inicial }- \text { atividade total residual) }}{\text { atividade total inicial }} \times 100$

Determinação da atividade hidrolítica e proteína total: A determinação da atividade da lipase foi feito por meio da reação de hidrólise utilizando $p$ NPP conforme metodologia 
descrita por Matte et. al (2014). A proteína solúvel foi determinada pelo método de Bradford (1976) utilizando albumina de soro bovino como padrão de proteína (BSA).

Estratégias: Foram realizadas 6 estratégias de imobilização, testando diferentes tipos de ativação. As estratégias estão demonstradas na Tabela 1.

Tabela 1 - Estratégias de Imobilização

Tipo de imobilização

I Ativação com glicidol + imobilização multipontual.

II Ativação com glicidol + imobilização unipontual.

III Ativação com glicidol + EDA + ativação com glutaraldeido + imob. multipontual.

IV Ativação com glicidol + EDA + ativação com glutaraldeido + imob. unipontual.

V Ativação com glutaraldeido + imobilização multipontual .

VI Ativação com glutaraldeido + imobilização unipontual.

Ativação com glicidol: Para a ativação das esferas de quitosana utilizando glicidol, uma quantidade de 100 esferas foram basificadas com 0,476 mL de $\mathrm{NaOH}$ 1,7 M. Após homogeneização, foi adicionado um agente redutor $\left(\mathrm{NaBH}_{4}\right)$, a frio. $\mathrm{O}$ meio básico e a adição do agente redutor são necessários para que a reação do glicidol com os grupos do suporte seja iniciada (SILVA, 2007). A adição de glicidol foi adicionada a uma proporção de $72 \%$ (v/p) da massa de suporte inicial, que ficaram em contato sob agitação por 18 horas a temperatura ambiente. Após esse tempo, as esferas foram lavadas com água destilada, e adicionou-se o agente oxidante, $\mathrm{NaIO}_{4}$ para transformar os grupos gliceril formados em grupos ativos.

Ativação com glutaraldeido: Para a ativação, seguiu-se o método descrito por Klein (2012), com alterações descritas a seguir. Uma quantidade de 100 esferas foi colocada em contato com $10 \mathrm{~mL}$ de uma solução de glutaraldeido 5\% em tampão pH 10 sob agitação por 2 horas a temperatura ambiente. Após esse tempo, as esferas foram lavadas com água destilada para total remoção do glutaraldeido não ligado.

Reação com ligação cruzada utilizando etilenodiamina (EDA): Com o intuito de aumentar a capacidade do suporte de imobilizar enzimas, utilizou-se a EDA. Segundo Silva, (2007), esta diamina se liga aos grupos aldeídos presentes no suporte após a ativação do suporte, deixando o outro grupo amino disponível para outro grupo amino da EDA é disponibilizado para a ligação de moléculas de glutaraldeído.

Imobilização da lipase de TLL: Para a imobilização da enzima no suporte, após a ativação, 100 esferas ficaram em contato sob agitação por 24 horas a temperatura ambiente com o extrato enzimático. Para imobilização covalente multipontual, a mistura era composta por TLL e tampão pH 10,5. Para a imobilização covalente unipontual, a mistura era composta por TLL e tampão pH 7.

Reação de transesterificação: Para a determinação da eficiência das estratégias de imobilização, foi utilizado o parâmetro de produção de biodiesel, a partir da reação de transesterificação catalisada por lipase. Para esta reação, utilizou-se $15 \%$ de derivado enzimático, etanol e óleo de soja na razão molar 6:1, e terc-butanol como solvente. Estes ficaram em agitação $(180 \mathrm{rpm})$ por 4 horas a $37^{\circ} \mathrm{C}$. As condições utilizadas foram baseadas em trabalhos anteriores (dados ainda não publicados). Após esse tempo, uma alíquota de 1 
$\mathrm{mL}$ foi misturada com água, e centrifugada. A fase superior, constituída pelo biodiesel foi analisada em cromatógrafo gasoso com detector de ionização de chama (FID) e uma coluna capilar DB-1, conforme condições descritas por Poppe (2015). A quantidade de FAEE (Fatty Acid Ethyl Esters) foi calculada utilizando o método de normalização compensada com padronização interna, com base na norma europeia EN 14103. Ao ser feita a realização de diversos usos, o derivado enzimático foi lavado 3 vezes com $10 \mathrm{~mL}$ de hexano entre as reações.

\section{RESULTADOS E DISCUSSÃO}

Iniciou-se as estratégias com carga proteica de $0,3 \mathrm{mg} / \mathrm{esfera}$. Estas foram analisadas em virtude do rendimento de imobilização e de produção de biodiesel. Como pode ser visto na Tabela 2, as estratégias I e II (ativação com glicidol) apresentaram um resultado muito baixo na produção de biodiesel. Apesar da estratégia I ter mostrado um rendimento de imobilização bem superior em relação ao rendimento de imobilização da estratégia II, essa diferença pode ter ocorrido em virtude da diferença de ligação unipontual (II) e multipontual (I). O baixo rendimento de biodiesel pode ter sido influenciado pela presença dos grupos glioxil resultantes da ativação, que além de serem poucos reativos à enzima, podem ter reagidos entre si tornando-se inativos (SILVA, 2012). Com isso, a ação catalítica da enzima foi reduzida, comprometendo a síntese de biodiesel.

Tabela 2 - Rendimento das imobilizações

\begin{tabular}{lcc}
\hline & Rendimento imobilização & Rendimento biodiesel \\
\hline Estratégia I & $63,1 \%$ & $2,6 \%$ \\
Estratégia II & $16,6 \%$ & $1,6 \%$ \\
Estratégia III & $93,2 \%$ & $2,9 \%$ \\
Estratégia IV & $94,1 \%$ & $3,3 \%$ \\
Estratégia V & $90,6 \%$ & $4,8 \%$ \\
Estratégia VI & $91,6 \%$ & $11,4 \%$ \\
\hline
\end{tabular}

As imobilizações mais eficazes para a produção de biodiesel foram as estratégias que utilizaram somente a ativação com glutaraldeído e que apresentam um elevado rendimento de imobilização. Nessas estratégias, os grupos aldeídos exibiram elevada reatividade, além de apresentarem alta afinidade com a enzima (ADRIANO et al, 2005). Como as estratégias V e VI tiveram destaque, aumentou-se a carga enzimática para $1,3 \mathrm{mg} /$ esfera afim de potencializar a atividade de síntese. Com essa carga, as estratégias V e VI apresentaram um resultado de $35,7 \%$ e $37,4 \%$ respectivamente na síntese de biodiesel.

A estabilidade operacional destes dois derivados foi avaliada para a escolha do melhor tipo de ligação covalente para a produção de biodiesel. Conforme pode ser visto na Figura 1, a estratégia $\mathrm{V}$ manteve praticamente toda a atividade enzimática inicial, mesmo após 10 usos, enquanto que a estratégia VI manteve somente $34 \%$ da atividade inicial na produção de biodiesel. 
Figura 1 - Reusos dos Imobilizados da Estratégia V e VI

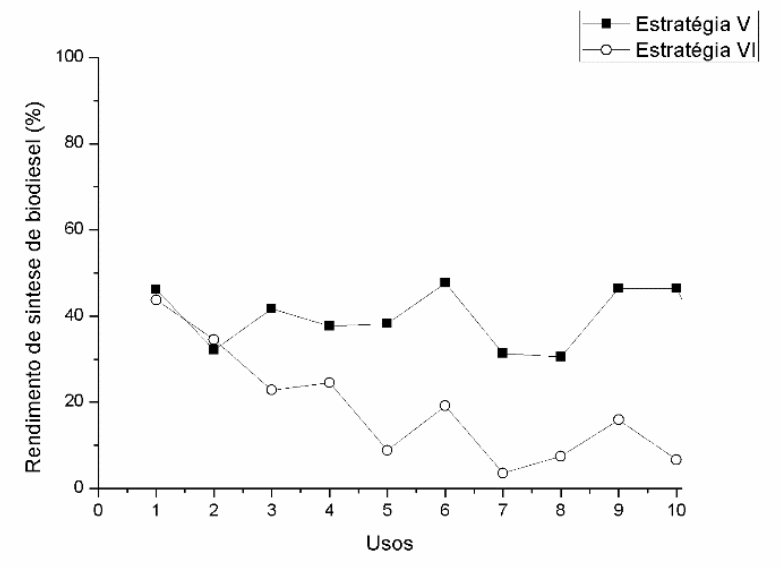

Os resultados obtidos demonstram que com os protocolos testados foi possível obter um rendimento de $47 \%$ na produção de biodiesel, o que é um resultado muito satisfatório para uma reação de apenas 4 horas, visto que se tem um estudo com rendimento de $91 \%$ com a mesma lipase imobilizada em quitosana, mas em 48 h de reação (MENDES, 2011).

\section{CONCLUSÃO}

O derivado enzimático produzido apresentou um excelente resultado para as reações de transesterificação utilizando o óleo de soja. A combinação da ativação com glutaraldeído das esferas de quitosana juntamente com a imobilização covalente unipontual resultou na produção de um derivado enzimático capaz de fornecer rendimentos mais elevados de biodiesel. Fatores ligados à estabilidade das enzimas que limitam a utilização desses biocatalisadores puderam ser superados neste trabalho, uma vez que a estratégia escolhida foi capaz de manter sua atividade inicial mesmo após diversos usos. Nesse sentido, os objetivos propostos neste trabalho puderam ser alcançados, demonstrando que a transesterificação enzimática utilizando enzimas imobilizadas é uma tecnologia promissora para a produção em grande escala de biodiesel.

\section{REFERÊNCIAS}

ADRIANO, W.S., MENDONCIA, D.B., RODRIGUES, D.S., MAMMARELLA, E.J.; GIORDANO, R.L.C. Improving the Properties of Chitosan as Support for the Covalent Multipoint Immobilization of Chymotrypsin. Biomacromolecules, 8, 2170, 2008.

ADRIANO, W. S.; FILHO, E. H. C.; SILVA, J. A.;GIORDANO, R.L.C; GONCALVES, L. R. B. Stabilization of penicillin $G$ acylase by immobilization on glutaraldehyde-activated chitosan. Braz. J. Chem. Eng., 22, 529-538, 2005.

ANTCZAK, M.; KUBIAK, A.; ANTCZAK, T.; BIELECKI, S. Enzymatic biodiesel synthesis - Key factors affecting efficiency of the process. Renew Energ, 34, 5, 1185-1194, 2009.

BRADFORD, M.M.A. Rapid and sensitive method for the quantification of microgram quantities of protein utilizing the principle of protein-dye binding. Anal. Biochem., San Diego, 72, 1-2, 248, 1976. 
CASTRO, H.F.D.; MENDES, A.A.; SANTOS, J.C.D.; AGUIAR, C.L.D. Modificação de óleos e gorduras por biotransformação. Quím. nova, 27, 146-156, 2004.

DEMIRBAS, A. Comparison of transesterification methods for production of biodiesel from vegetable oils and fats. Energy Conversion and Management, 49, 1, 125-130, 2008.

EN, 14103: Fat and Oil derivatives - Fatty Acid Methyl Esters - Determination of esters and linolenic acid methyl esters content. European Committee for Standardization: 2001.

GARCIA, T.; COTERON, A.; MARTINEZ, M.; ARACIL, J. Kinetic model for the esterification of oleic acid and cetyl alcohol using an immobilized lipase as catalyst Chem. Eng. Sci., 55, 1411, 2000.

KLEIN, M.; NUNES, M.; RODRIGUES, R.; BENVENUTTI, E.; COSTA, T, HERTZ, P. Effect of the support size on the properties of galactosidase immobilized on chitosan: Advantages and disadvantages of macro and nanoparticles. Biomacromolecules, 13, 2456$2464,2012$.

KOPP, W. Síntese e ativação superficial de novos suportes magnéticos para imobilização de enzimas / William Kopp - São Carlos: Tese de doutorado, UFSCar, 2014.

MATTE, C.; BUSSAMARA, R.; DUPONT, J.; RODRIGUES, R.; HERTZ, P.; AYUB, M. Immobilization of Thermomyces lanuginosus Lipase by Different Techniques on Immobead 150 Support: Characterization and Applications. Appl. Biochem. Biotechnol., 1-14, 2014.

MENDES A.A.; GIORDANO R.C.; GIORDANO R.L.C.; DE CASTRO H.F. Immobilization and stabilization of microbial lipases by multipoint covalent attachment on aldehyde-resin affinity: application of the biocatalysts in biodiesel synthesis. J Mol Catal B: Enzym. 68:109$15,2011$.

MENDES, A.A.; CASTRO, H.F. DE, GIORDANO, R.L.C.. Triagem de suportes orgânicos e protocolos de ativação na imobilização e estabilização de lipase de Thermomyces lanuginosus. Quím. Nova [online], 36, 2, 245-251, 2013.

POPPE, J.K.; GARCIA-GALAN, C.; MATTE, C.R.; FERNANDEZ-LAFUENTE, R.; RODRIGUES, R.C.; AYUB M.A.Z. Optimization of synthesis of fatty acid methyl esters catalyzed by lipase B from Candida antarctica immobilized on hydrophobic supports. $J \mathrm{Mol}$ Catal B-Enzym, 94, 51-56, 2013.

POPPE, J.K.; MATTE, C.R.; BERALBA, M.C.R.; FERNANDEZ-LAFUENTE, R.; RODRIGUES, R.C.; AYUB, M.A.Z. Optimization of ethyl ester production from olive and palm oils using mixtures of immobilized lipases. Appl. Catal. A-Gen., 490, 50-56, 2015.

SILVA, J.A.; MACEDO, G.P.; DRODRIGUES, S.; GIORDANO, R.L.C.; GONCALVES, L.R.B. Immobilization of Candida antarctica lipase B by covalent attachment on chitosanbased hydrogels using different support activation strategies, Biochem. Eng. J., 60, 16-24, 2012. 